América Latina 



\title{
Reflexiones sobre Chile: ¿hay alternativas al modelo neoliberal?
}

\author{
JACQUES CHONCHOL
}

$\mathrm{E}$

l PENSAMIENTO ECONÓMico dominante hoy en América Latina y que, en gran parte, se da en Chile es el pensamiento neoliberal, cuyas ideas básicas son las siguientes:

- El crecimiento máximo del producto nacional bruto es lo esencial desde el punto de vista del desarrollo de la economía y en la medida en que esto se logre de un modo continuado, se van a resolver todos los problemas económicos y sociales del país.

- Este crecimiento depende, fundamentalmente: a) del dinamismo del mercado, el más eficiente asignador de los recursos disponibles, y b) de la actividad del sector privado. El gobierno no tiene a este respecto sino que un rol subsidiario.

- Siendo el gobierno ineficiente por naturaleza desde el punto de vista del manejo de las actividades productivas, debe proceder a privatizar todas las empresas que aún hoy día controla e inclusive numerosos servicios, en los cuales anteriormente tenía una gran responsabilidad (salud, previsión, educación, obras públicas, agua potable, correos etc.).

- Hay que abrir al máximo las fronteras para las mercancías, los capitales y los flujos financieros del exterior. Todo ello conducirá a que las empresas que subsistan sean competitivas y de alta productividad, y las empresas ineficientes y caras desaparecerán o se reconvertirán.

- La atracción de capital extranjero es fundamental dada la insuficiencia del ahorro y del capital nacionales. Esto permitirá aumentar la inversión, el empleo, modernizar con nuevas tecnologías todas las actividades productivas y de servicios. Se logrará así la mayor prosperidad para todos.

- Para que el crecimiento continuado y estable pueda proseguirse es fundamental el equilibrio de las grandes variables macroeconómicas 
(reducción de la inflación, equilibrio de la balanza de pagos, control del gasto y del déficit fiscal, tener una tasa de interés razonable y un tipo de cambio apropiado).

- También es necesario, para activar la economía, incrementar las tasas de ganancia que son necesarias para incentivar la inversión privada. Esto requiere flexibilizar y suprimir las rigideces de origen político e institucional que distorsionan la eficaz asignación de los recursos. Estas rigideces son el excesivo poder de los sindicatos, las legislaciones proteccionistas, la intervención gubernamental, los costos excesivos de los programas sociales que, además de generar presiones inflacionarias, desincentivan el empleo y socavan la disciplina laboral.

- Además, en el caso chileno, el dinamismo del crecimiento está ligado al aumento de su capacidad exportadora. Esta ha aumentado con gran rapidez en los últimos años, habiendo más que duplicado entre 1987, en que las exportaciones de bienes y servicios alcanzaron a US\$ 6.309 millones y 1994 en que subieron a US\$14.507 millones.

- Un elemento muy importante del modelo neoliberal que no se reconoce abiertamente pero que se tolera con facilidad son las grandes diferencias en la distribución del ingreso. Las desigualdades que existen en toda sociedad son consideradas algo positivo porque constituyen una fuente de dinamismo económico. No se dice abiertamente que se es partidario de la desigualdad, pero se cree que ésta ayuda al crecimiento económico y que este crecimiento, en un momento de la historia, cuando sea suficientemente importante, resolverá por desborde la situación de los más pobres y los inconvenientes de los excluídos de los beneficios actuales del crecimiento. En Chile, por supuesto, con respecto a este aspecto, hay diferencias fundamentales entre, por ejemplo, el pensamiento de El Mercurio (símbolo máximo de este neoliberalismo) y aquéllos que se preocupan del problema de la pobreza y de la extrema pobreza. Pero más allá de estas diferencias, existe una gran tolerancia de todos hacia la gran desigualdad en la distribución de los ingresos.

- Otra idea dominante del pensamiento neoliberal es el rol extraordinariamente selectivo que se tiene del Estado. Este es, en general, considerado una carga y hay que liberar a la sociedad del peso aplastante del Estado, sobre todo en materia de impuestos y de reglamentaciones. Pero cuando se ven afectados los intereses de los privilegiados, el Estado ya no es mirado como una carga, sino como una entidad que tiene que desempeñar un papel activo para ayudarlos a salir adelante. Recordemos el caso famoso del apoyo a los bancos en 1983, en que el Banco Central compró la cartera vencida para evitar la quiebra de 22 bancos privados 
por la suma de US\$ 5.700 millones de la época, lo que ha dado origen al problema actual de la deuda subordinada. Como lo señalaba muy bien hace un par de años el gran economista norteamericano John Kenneth Galbraith a propositonde los Estados Unidos, "los gastos sociales que benefician a los ricos, los salvavidas financieros, los gastos militares y, por supuesto, el reembolso de los intereses acumulados, gastos todos que constituyen en el presupuesto federal de la parte más importante, son perfectamente aceptados. Pero los otros gastos sociales, los que favorecen a la habitación popular, los gastos médicos para aquellos que no gozan de ninguna protección, los destinados a la enseñanza pública y a las diversas necesidades de las grandes zonas urbanas desfavorecidas, eso constituye el peso inaceptable de los gastos públicos" en el pensamiento neoliberal.

- Finalmente, cabe señalar que en este pensamiento no existe ninguna preocupación, o casi ninguna, por las consecuencias y los costos indirectos del sistema productivo en materia de impactos en el medio ambiente, de agotamiento de los recursos naturales, de los efectos sociales y ecológicos. Todos estos son problemas del futuro y del largo plazo y lo que interesa al neoliberalismo es la rentabilidad inmediata. No existe, tampoco, ninguna preocupación por el conjunto de políticas que podríamos englobar bajo el título de defensa del patrimonio nacional.

Estas son, en síntesis, las principales creencias o principios de la economía neoliberal que hoy dominan en el pensamiento económico mundial y latinoamericano, por supuesto con matices desde un neoliberalismo puro y duro que se cree ciencia económica a otro que trata de corregir algunos de sus impactos en lo social. Esta ideología que es casi una teología también ha penetrado de un modo significativo la mentalidad chilena, aún entre aquellos que se dicen de centro o de izquierda (la línea divisoria entre los neoliberales y los que no lo son pasa al interior de los partidos de la concertación).

\section{Causas de la penetración}

\section{y desarrollo del neoliberalismo}

¿Cuáles son los factores y causas que han impulsado esta dominación mundial de las ideas neoliberales?

Me parece que es posible señalar un conjunto de factores que se produjeron en el mundo desde fines de la década de los ' 70 y comienzos de los ' 80 , todos los cuales han contribuido a esta situación.

- Por un lado, la respuesta de tipo extraordinariamente conservadora que se produjo en dos de los grandes países desarrollados a la crisis del esta- 
do de bienestar (con gastos que aumentaban más rápidamente que los recursos y con déficits públicos que presionaban la inflación). Me refiero a los Estados Unidos de Norteamérica bajo el gobierno de Ronald Reagan (la reaganomanía) y a Inglaterra, bajo el largo gobierno de Margaret Thatcher (el thatcherismo). Las políticas de estos gobiernos y sus ideas se propagaron primero en sus países de origen y penetraron, enseguida, con fuerza en el plano internacional y en los organismos financieros internacionales. En América Latina, estas políticas están en pleno auge con cierto retraso con respecto al mundo desarrollado, y cuando en éste son cada vez más criticadas.

- El neoliberalismo ocupó, desde el punto de vista intelectual, el espacio que tenían antes en los países en desarrollo las teorías estructuralistas y, en la situación particular de América Latina, la teoría de industrialización por substitución de importaciones que propagó la Cepal. Del mismo modo, reemplazó a otras teorías de la modernización de los países en desarrollo, como fue la famosa teoría de las etapas del crecimiento de Walter Rostow.

- Otro factor que contribuyó de un modo muy importante a la dominación ideológica del neoliberalismo ha sido la desaparición de las utopías colectivistas y de la planificación centralizada como consecuencia de la crisis de los regímenes comunistas a fines de los años ' 80 (caída del muro de Berlín, desaparición de la URSs), así como las dificultades y fracasos económicos en muchos países del tercer mundo que trataron de aplicar sistemas socialistas más o menos inspirados en los de Europa del Este.

- Otro elemento de impulsión del neoliberalismo fue la crisis de la deuda con moratoria mexicana de 1982. Las limitaciones fiscales y la falta de nuevos capitales condujo a una crisis financiera considerable y muchos países tuvieron que aceptar para salir de ella las políticas de ajuste impuestas por el FMI (reducción de los gastos fiscales y de subsidios diversos, privatizaciones de las empresas públicas o semipúblicas, liberalización del comercio externo etc.). Los países latinoamericanos que, al comienzo de la crisis de la deuda en los años ' 80 habían hablado de una renegociación colectiva de dicha deuda, pronto plegaron a negociar uno por uno y aceptaron todas las condiciones impuestas por el Fondo Monetario Internacional y por los organismos financieros. Vale la pena señalar, de paso, que el meyor alumno de esta única vía de solución impuesta por el FMI y el ejemplo más citado como buen alumno de la ortodoxia económica, es el caso de México, que acaba de tener un nuevo reventón financiero que ha puesto en serio peligro su salud económica y 
su estabilidad política. Para escapar de la quiebra, necesita nuevamente una ayuda cercana a los US\$ 50 mil millones, y ha tenido que devaluar brutalmente su moneda, dar garantías con su petróleo al capital norteamericano, y lo amenaza una crisis del empleo colosal. Este es el México que una semana antes de la crisis, el muy prestigioso banco de Nueva York Salomon Brothers calificaba, en diciembre último, como una economía en un estado muy positivo, y que la agencia financiera mundial Moody's Investors Service, que clasifica los Estados según las garantías o riesgos para los inversores extranjeros, consideraba como una economía muy segura.

- Finalmente, se puede señalar como otro factor de impulso del neoliberalismo la aparición, dentro de los países latinoamericanos, de nuevas élites tecnocráticas, como los Chicago Boys en Chile y los economistas que rodearon al ex-presidente Salinas de Gortari en México, inspirados en la Escuela de Chicago y en las teorías monetaristas de Milton Friedmann. Todos ellos han tenido mucha influencia en otros países de América Latina.

\section{Las críticas al neoliberalismo}

Una de las críticas más agudas a el neoliberalismo es aquella hecha, recientemente (en 1992), por el gran economista norteamericano John Kenneth Galbraith en su libro The culture of contentment. Según Galbraith existe en los Estados Unidos una minoría satisfecha que domina el sistema político y que en términos nacionales es una minoría, pero que constituyen la mayoría de los que participan en las elecciones y votan y, através de ello, influencian decisivamente la política del país.

Para esta minoría de satisfechos, las ideas esenciales de una economía sana son las siguientes:

- La buena fortuna es la recompensa al mérito de los que gozan de ella. Es el resultado de la capacidad moral o intelectual de los que la han obtenido.

- Esta minoría satisfecha prefiere siempre la inacción del Estado, aún si las consecuencias de esta inacción pueden ser alarmantes a largo plazo. La razón es evidente: el costo inmediato de la acción preventiva del Estado para salvaguardar el largo plazo recaería sobre los actuales privilegiados al aumentarse, por ejemplo, los impuestos. En cuanto a los beneficios a largo plazo, seguramente los que los aprovecharán serán otros. Según la teología del laissez-faire que inspira a estos satisfechos todo terminará por arreglarse. 
- Tercera idea de estos satisfechos ya la señalamos anteriormente. El Estado es una carga en todo lo que beneficia a los pobres, pero su acción es necesaria cuando las dificultades afectan a los ricos.

- Finalmente, según Galbraith, la minoría satisfecha soporta, con gran tolerancia, las grandes diferencias en la distribución del ingreso. La posibilidad que los ricos continúen enriqueciéndose, aún si los pobres no meyoran su situación o continúan empobreciéndose, es un estimulante fundamental para el crecimiento y el dinamismo de la economía. En la ciencia económica que propicia la minoría satisfecha, la política monetaria desempeña un rol privilegiado. Tiene la ventaja de no exigir, prácticamente, ningún aparato administrativo salvo el insignificante aparato burocrático del Banco Central. La política monetaria es considerada el instrumento básico para prevenir o controlar la inflación o la recesión. En cuando al hecho de que la política monetaria es una manera de desviar la acción del Estado de las zonas inconfortables de la política fiscal, de la de gastos públicos, del control de precios o de los sueldos y salarios y que recompensa, sobre todo, a la clase de los rentistas, no siendo neutra en el plano económico, nada se dice y el silencio es absoluto.

Una segunda crítica muy aguda del neoliberalismo es la que hace el economista francés Michel Albert, presidente de la compañía AGF (Seguros Generales de Francia) en su libro Capitalismo contra capitalismo, publicado en 1991.

Hablando de las tres etapas del capitalismo, señala que su primera etapa $o$ fase fue la del capitalismo contra el Estado, que se inició en 1791 con la Revolución Francesa. La legislación de la época suprimió las corporaciones que venían desde la edad media, prohibió los sindicatos y estableció la libertad de comercio y de industria. Durante el siglo XIX, el Estado retrocedió frente a las fuerzas del mercado concentrándose en la función de Estado policial encargado de proteger el orden público contra las clases peligrosas, constituidas por el nuevo proletariado industrial. Se asiste, al mismo tiempo, a la explotación del hombre, al desarraigo del antiguo mundo campesino, a la opresión económica a la clase obrera y a las durezas sociales de la revolución industrial.

Este capitalismo es el que denuncia Marx en Manifiesto Comunista y contra el cual reaccionan las iglesias Protestante y Católica (Encíclica Rerum Novarum de León III en 1891, por ejemplo).

En este último año, empieza la segunda fase del capitalismo, que es del capitalismo encuadrado por el Estado. Todas las reformas se dirigen a corregir los excesos del mercado y a temperar las violencias del capitalismo. El Estado aparece como el refugio contra lo arbitrario y lo injusto y es él, bajo la presión de las 
luchas obreras, quien, mediante leyes y decretos, humaniza las brutalidades del capitalismo por la legislación del trabajo, el aumento continuo de la fiscalidad y los sistemas de redistribución.

Pero, desde hace algunos años, el orden de prioridades parece haber cambiado. El Estado no aparece más como un protector sino como un parásito, un freno, un peso muerto. Hemos entrado en una tercera fase que se puede denominar la del capitalismo en lugar del Estado. Los principios básicos son los del neoliberalismo y se resumen en pocas palabras: el mercado es bueno, el Estado es malo, mientras la protección social era considerada como un criterio de progreso de la sociedad, se la denuncia ahora como un incentivo a la flojera y un obstáculo al esfuerzo; mientras que el impuesto era considerado como un medio esencial de conciliar desarrollo económico y justicia social, es hoy día acusado de frentar la acción de los más dinámicos, de los más audaces. Hay, pues, que reducir los impuestos y las cargas sociales y desreglamentar, es decir, hacer retroceder al Estado en toda línea para que el mercado pueda liberar las energías creadoras de la sociedad. No se trata ahora, como en el siglo XIX, de oponer el capitalismo al Estado, se trata de reducir al máximo el campo de acción de éste y de substituirle las fuerzas del mercado. En el siglo XIX el capitalismo no podía tomar el lugar del Estado, ni en el campo de la salud, ni de la enseñanza, ni de la información, por la simple razón que las escuelas, los hospitales y los diarios dependían de la iniciativa privada. Pero en nuestra época, en la mayor parte de los países desarrollados, se trata de que todas estas actividades, empezando por la radio y la televisión, pasen del sector público al sector privado, desde el servicio de agua potable hasta el correo y la recolección de basuras.

Esta nueva fase del capitalismo en lugar del Estado, junto con la globalización de la economía y sobre todo de las finanzas, que ya nadie parece poder controlar, y que hace que los gestionarios de fondos de pensiones y de seguros y de fondos comunes de colocación, que disponen de recursos líquidos inmensos, que desplazan rápidamente de un mercado a otro, según las circunstancias, con el fin de realizar ganancias especulativas, ha creado un desorden financiero y económico de enormes consecuencias sociales.

Al mismo tiempo que disminuyen los recursos de protección de los trabajadores, en los veinticinco países más ricos del mundo (los de la OCDE) había, en 1994, 36 millones de cesantes. Y cuando se logran crear muchos empleos, como en los Estados Unidos y en Gran Bretaña, éstos son de bájísima productividad y con una disminución de los salarios reales.

El mecanismo de la pobreza y de la exclusión ligado a este neoliberalismo dominante ya no es un misterio para nadie. Por una parte, el exacerbamiento de la competencia internacional, que lleva a numerosas reestructuraciones industriales, al despido de trabajadores, al aumento de la cesantía y de la duración 
del período en que los trabajadores quedan cesantes, a la multiplicación de los empleos precarios y mal pagados, a la modernización tecnológica, que multiplica los inaptos frente a los nuevos sistemas de producción. Por otra parte, sistemas de protección social que se hacen cada vez más inadaptados al aumento de la pobreza cuando no son reducidos por los gobiernos preocupados por los equilibrios macroeconómicos. Cuando los dos procesos se combinan y se desagregan las solidaridades tradicionales, baseadas sobre la familia, el barrio o la aldea, la exclusión gana terreno. En 1992, en los doce países de la CEE, había 50 millones de pobres, de los cuales 10 millones en Gran Bretaña (el 18\% de la población de ese país). En Estados Unidos, el 1\% de las familias más ricas acaparó el 70\% de los ingresos medios familiares entre 1977 y 1989. El 20\% más rico se alzó con más del 100\% del crecimiento a expensas del $40 \%$ más pobre. Las políticas de Reagan y de Bush, afirman Donald Barlett y James Steele, en su libro America ; What went wrong, resultado de un trabajo de dos años en 50 ciudades de 16 estados "han acelerado el desmantelamiento de la clase media norteamericana. Sólo se pueden encontrar dos antecedentes similares, en 1913, cuando el descontento llevó a adoptar el primer impuesto progresivo sobre la renta, y en 1933, el año en que la crisis condujo al New Deal".

Una tercera crítica al neoliberalismo, también en el contexto de la mundialización de la economía, es la que hace Robert Reich, el actual ministro de trabajo del presidente Clinton en su obra The wealth of Nations, publicada en 1991 .

Reich muestra que la transformación acelerada de las grandes empresas mundiales, las hace pasar de la empresa de producción de masa a un nuevo tipo de empresa organizada en forma de pequeñas unidades autónomas, relacionadas mediante redes constituidas por una multitud de grupos y subgrupos descentralizados, todos los cuales operan mediante acuerdos con otras unidades de producción igualmente difusas. Este moderno sistema de producción está dividiendo los empleos en los países desarrollados en tres grandes categorías: los empleos de producción corriente, los servicios personales y los empleos que Reich denomina de los "manipuladores de símbolos".

Mientras que los primeros y los segundos se empobrecen: trabajadores de la producción en cadena, o dedicados a los servicios personales (enfermeras, policías, cajeros, vendedores etc.), los terceros constituidos por los investigadores, los ingenieros, los informáticos, los abogados de las grandes empresas, los consejeros financieros o fiscales, los publicistas etc., se enriquecen cada vez más. El conjunto de estos últimos representaban en los Estados Unidos, en 1990, el $20 \%$ de la fuerza de trabajo. El $80 \%$ restante estaba en la categoría de los que se empobrecen. Esta divergencia de situación y de ingresos está destruyendo la idea de solidaridad nacional y aumenta la distancia entre los manipuladores de símbolos que se enriquecen, cada vez más, y los excluídos en su propio país. Para Reich 
esto exige un conjunto de respuestas simultáneas, que van desde la compensación por un impuesto progresivo sobre el ingreso a una política educativa y de inversión pública de intensidad creciente.

Una cuarta crítica al neoliberalismo proviene de aquellos que podemos reagrupar bajo la égida de defensores de un desarrollo durable. Estos, preocupados por el egotamiento creciente de los recursos naturales, por la destrucción inmoderada de los bosques y florestas, por la degradación de los suelos, por el adelgazamiento de la capa de ozono y por las amenazas a la biodiversidad, critican no solamente las consecuencias del neoliberalismo dominante, sino también la utopía industrializante heredada, tanto de la modernización capitalista como de lo que fue la modernización de los ex-países comunistas del Esteeuropeo. La idea central de esta crítica proviene de la creencia de que un desarrollo durable no puede hacerse, ni en detrimento de las próximas generaciones, ni en detrimento de la salud ecológica del planeta.

Las críticas al neoliberalismo, desde este punto de vista, son numerosas, tanto en los países ricos y desarrollados, como en los países en desarrollo. Entre los primeros podemos destacar al Worldwatch Institute de los Estados Unidos y a su director Lester Brow, que han hecho numerosas publicaciones en torno a la idea de construir una sociedad sustentable. Entre los segundos, podemos señalar a la comisión de los países del Sur, presidida por el ex-presidente de Tanzania Julius Nyerere y constituida por un grupo destacado de economistas, políticos e intelectuales de los países del Sur que, en su conocido informe institulado Desafíos para el Sur, explicó en 1990 las condiciones viables para el desarrollo de estos países. Entre muchos otros aspectos afirmaron: "las estrategias de desarrollo de los países del Sur deben considerar que el capital natural del planeta es limitado. El concepto de desarrollo viable tiene por objetivo llamar la atención sobre la necesidad de conciliar crecimiento y protección del medio ambiente y debe considerarse negativa toda modernización económica de óptica inmediata y estrecha. Una voluntad no reflexiva de modernización a cualquier precio puede causar daños irreparables a los sistemas ecológicos. La degradación de los suelos, la polución de las aguas y la desforestación, representan una gran amenaza para el desarrollo a largo plazo de los países del Sur".

Una quinta crítica al neoliberalismo proviene de ciertos organismos internacionales, como el PNUD de las Naciones Unidas que considera que la mayor parte de los criterios tradicionales para medir el crecimiento económico y el progreso están deformados por una visión demasiado economicista de la realidad social. Proponen, en cambio, nuevos indicadores para medir el progreso, no solamente material, sino también de la calidad de la vida. Estos indicadores han sido englobados bajo el concepto de indice de desarrollo humano. ¿Que és el desarrollo, según este concepto? Disponer de un mayor ingreso, por supuesto 
que si, pero él no es un fin en sí mismo, es un medio de adquirir bienestar. $L a$ esperanza de vida, la libertad politica, el acceso al saber, la seguridad física, la participación en la vida de la comunidad, el ejercicio de los derechos humanos, forman parte del bienestar. El desarrollo no se reduce al hombre económico. La vida no comienza a partir de tantos dólares por habitante-año como ingreso medio.

Para medir cuantitativamente el desarrollo, el PNUD creó un nuevo instrumento: el indice de desarrollo bumano, que es un agregado de diferentes indicadores, que se reflejan tres componentes esenciales de la vida del hombre: la longevidad, el saber y el nivel de vida. La longevidad es medida por la esperanza de vida al nacer, el saber por un índice en el cual interviene la tasa de alfabetización de los adultos y el número promedio de años de estudio, y el nivel de vida por el poder de compra, determinado por el producto por habitante ponderado por el costo de vida.

El PNUD considera que este indicador es aún imperfecto, pero en todo caso es muy superior a la tradicional medición de tantos dólares por habitanteaño. Este nuevo indicador demuestra que crecimiento económico y progreso humano no están ligados automáticamente. Es, por ejemplo, absurdo y peligroso, desde el punto de vista del desarrollo humano, suprimir los subsidios a la alimentación y la salud de los pobres en nombre del liberalismo económico, en los países donde no existe un sistema de seguridad social compensador.

Una sexta crítica al neoliberalismo ha sido desarrollada, sobre todo en América Latina, por la Cepal. Mientras que el neoliberalismo propone dejar al mercado y al sector privado la responsabilidad del crecimiento económico y no pone ningún acento en la equidad, la Cepal nos dice que la experiencia permite comprobar que el crecimiento económico no conduce, de manera necesaria y automática a la equidad. Para ello, el crecimiento con equidad, ambientalmente sustentable y en democracia, no sólo es deseable, sino también posible. Es más: así como la equidad no puede alcanzarse con ausencia de un crecimiento sólido y sostenido, el crecimiento exige un grado razonable de estabilidad socio-política, y ésta implica, a su vez, cumplir con ciertos requisitos mínimos de equidad. De este condicionamiento recíproco, entre crecimiento y equidad, se desprende la necesidad de avanzar hacia ambos objetivos en forma simultánea antes que secuencial, lo que constituye un desafío histórico.

Una séptima y última crítica proviene de otros organismos internacionales como la Unicef. Bajo el título de Ajuste con rostro humano, esta organización de las Naciones Unidas afirma que las políticas de ajuste económico, que gran número de países en desarrollo han adoptado para hacer frente a la crisis económica, deben considerar las incidencias en el plano humano que estas políticas pueden tener. Toda política de ajuste económico debe tener en consideración las 
necesidades esenciales de los grupos más vulnerables en materia de salud, alimentación, educación y preservación del bienestar de estas poblaciones. Toda política de ajuste que no dé especial consideración a estos poblemas será negativa desde el punto de vista del desarrollo.

\section{Consecuencias sociales del modelo económico neoliberal aplicado en Chile}

El modelo económico neoliberal se viene aplicado en Chile desde de la época de la dictadura militar y con algunos ajustes sociales se ha seguido aplicado bajo los dos gobiernos democráticos que le han sucedido.

Se ha puesto mucho énfasis en sus éxitos económicos:

- Crecimiento sostenido de la economía desde hace unos diez años e importante mejoramiento del ingreso medio por habitante. Este aumentó en casi $12 \%$ entre 1981 y 1990, mientras en la mayor parte de los países latinoamericanos el ingreso por habitante bajaba en esos años, como consecuencia de la crisis. Entre 1991 y 94, bajo los gobiernos democráticos, el ingreso por habitante aumentó en casi $20 \%$.

- Disminución de la tasa de inflación de más de 20\% al final de los años '80 (27,3\% en 1990) a sólo 8,9\% en 1994 .

- Disminución de la tasa de desempleo urbano de más de 13\% en 1986 a un 4\% en 1993, subiendo a sólo poco más de 6\% en 1994.

- Gran dinamismo y aumento de las exportaciones, como ya lo indicamos anteriormente.

- Considerable tasa de inversión, con gran afluencia de capitales externos y buenos equilibrios macroeconómicos.

A lo anterior, hay que agregar, desde el punto de vista social, a partir de la llegada del primer gobierno democrático, una disminución sustancial del número de pobres.

Utilizando el método de la línea de pobreza, es decir, el ingreso corriente de los hogares, el número de pobres en Chile era em 1987 igual a 5,498 millones personas (casi el 45\% de la población) y en 1992 de 4,370 millones personas (el $33 \%$ ). Es todavia grave que un tercio de la población viva bajo la línea de la pobreza, pero era mejor la situación en 1992 que en los años anteriores (éste es el último año para el que hay estadísticas disponibles sobre pobreza).

Conviene, por otra parte, agregar que el método de la línea de pobreza tiene una limitación. Procede como se la satisfacción de las necesidades básicas 
dependiera sólo del ingreso corriente de los hogares, cuando que tengan las familias a bienes y servivios gubernamentales, a la educación, a la salud y a la vivienda. Aplicando un indicador más completo: el método integrado de medición de la pobreza se llega a la conclusión que en 1992 un 50\% de los hogares urbanos tenía aún algún tipo de carencia (agua por acarreo, mutos de desechos o en mal estado; hogares en los que algún miembro necesitó atención médica, la solicitó y no la obtuvo; más de una familia viviendo en la misma vivienda etc.).

Las razones de la disminución de la pobreza durante los gobiernos democráticos han sido varias: fuerte aumento del implementación de diversos programas sociales y menor aumento de los precios de los productos que componem la canasta básica de alimentos, en comparación con los precios promedios de la economia.

Pero, a pesar de estos aspectos positivos de la sociedade chilena, que se deben a ciertos ajustes hechos al modelo neoliberal por los gobiernos democráticos, éste sigue teniendo numerosas consecuencias muy negativas para el futuro del país.

\section{Impactos negativos del modelo exportador en los trabajadores y en el medio ambiente}

En los últimos diez años son importantes y evidentes los avances en el crecimiento y expansión de los sectores fruticola y pesquero.

En el caso de la fruta, a pesar de las crisis que se producen de vez en cuando (caso de las uvas envenenadas, tipo de cambio que, según los exportadores, frena hoy las utilidades necesarias para la mayor expansión del sector), todos están de acuerdo en señalar el importante aumento del valor de estas exportaciones (US\$ 500 millones en 1987, US\$ 982 millones em 1992).

De lo que no se habla es de las condiciones en que se producen estas frutas. Recientes investigaciones auspiciadas por la organización OXFAM de Inglaterra y realizadas por científicos chilenos nos aportan interesantes antecedentes.

Siendo la producción de frutas de exportación parte de un sistema altamente competitivo, se han ido adoptando paquetes tecnológicos que sobreutilizan insecticidas, hierbicidas y fertilizantes. En el país, se comercializan 972 pecticidas y el monto de sus importaciones alcanzó a US\$ 71 millones en 1992. Varios de ellos: el Paration, el Lindano, y el Paraquat forman parte de doce pecticidas conocidos en el mundo con el nombre de docena maldita y están considerados como sumamente tóxicos.

El Paraquat está clasificado por la Agencia Ambiental de los Estados Unidos como extremadamente tóxico, tanto para los seres humanos, como para los mamíferos y peces. 
El Paration, se estima que causa la mitad de las muertes por intoxicación aguda producidas por plaguicidas en el mundo, y en Chile se usa extensamente.

El Lindano está cancelado en los Estados Unidos por ser embriotóxico y cancerígeno

La mayor parte de estos productos son elaborados por multinacionales que, además, se han diversificado hacia la producción de otros insumos, como las semillas híbridas de alto rendimiento, sin resistencia genética a las plagas, por lo que requieren grandes cantidades de plaguicidas para sus cultivos, plaguicidas que son producidos por las mismas empresas que producen las semillas.

El uso frecuente e irracional de plaguicidas, además de destruir, junto con las plagas, las especies benéficas para el hombre, producen graves daños a los trabajadores frutícolas mediante intoxicaciones frecuentes. En el Hospital de San Felipe, por ejemplo, en el centro de la zona frutícola de Aconcagua, se debe atender anualmente gran número de trabajadores con diversos síntomas de intoxicación, dados los equipos de protección insuficientes y la falta de capacitación, a este respecto, de los propios trabajadores.

En el Hospital de Rancagua, en estudios ahí realizados, se hace referencia a las malformaciones congénitas de niños recién nacidos como consecuencia de las exposiciones de las madres a los agrotóxicos.

La aplicación de plaguicidas, al contaminar las aguas y el aire, no sólo afecta la salud de los trabajadores de la fruta, sino de toda la población que vive a los alrededores. Sin embargo, la regulación de su uso es, en el país, muy deficiente. La tarea de fiscalización, que corresponde a los ministerios de salud y de trabajo, no se ejecuta adecuadamente por la carencia de personal capacitado, debido a la jibarización del aparato del Estado.

En cuanto a los trabajadores que son empleados en la fruticultura, en su inmensa mayoría son temporeros (por cada permanente hay tres temporeros) y una buena parte está constituida por mano de obra femenina, especialmente en el caso de la uva.

Más de $50 \%$ de los temporeros laboran sin contrato y muchos empleadores no cumplen, o se burlan de las obligaciones legales en materias de horario de trabajo, pago de horas extraordinarias, pago de la semana corrida y bonificaciones, descansos, pago de vacaciones proporcionales. En el peak de producción se hacen, a veces, jornadas de doce y hasta dieciseis horas.

Las remuneraciones brutas promedio de los trabajadores de temporada tienden a ser superiores a las del salario mínimo legal mensual, pero ello se logra con jornadas extremadamente largas, a un ritmo de trabajo agotador y bajo un ambiente laboral deficiente. 
La actual legislación laboral excluye a los trabajadores temporeros de la posibilidad de negociar colectivamente. Al 30 de junio de 1992, sólo se consignaban 9.238 temporeros sindicalizados en instituciones, casi nunca propias sobre una masa de más de 300 mil.

Al trabajador frutícola sólo se le paga el salario por el tiempo o la tarea desempeñada, lo cual no alcanza para su mantención durante los períodos de inactividad.

En el caso de la pesca el sector ha tenido también un desarrollo espetacular. Los desembarques de productos del mar se quintuplicaron entre 1970 y 1990, pasando de 1 millón a más de 5 millones de toneladas. Chile se ubica hoy entre los cinco primeros lugares en nivel mundial en lo que a captura se refiere.

Pero numerosos técnicos señalan que buena parte de esta expansión se ha hecho mediante la sobreexplotación del patrimino natural de los recursos marinos, los que se extraen con objetivos de máxima ganancia, sin consideraciones conservacionistas ni de protección ecológica. Esta situación plantea un muy serio problema de sustentabilidad del crecimiento del sector pesquero, a mediano y largo plazo.

La intensificación del esfuerzo de algunas capturas ha tenido efectos críticos en las poblaciones de peces, algunas de las cuales han llegado a colapsar. Son los casos de la anchoveta, la sardina española y la sardina común, todas especies muy cotizadas para la producción de harina y aceite de pescado de exportación.

Los científicos denuncian que los resultados de la sobrepesca son prácticamente irreversibles pues, al desaparecer una especie o bordear su extinción, se producen cambios en los ecosistemas marinos difíciles de recuperar.

Esto se hace evidente en el caso de otras especies en extinción: locos, erizos, jaibas, centollas y gran variedad de peces costeros.

Varios son los factores que contribuyen a profundizar el agotamiento de las especies marinas:

- El sobredimensionamiento de la flota pesquera y del parque industrial.

- La realización de la mayor parte de las actividades de la flota pesquera en las proximidades de la costa.

- El uso de métodos de pesca no selectivos.

- La presión de los mercados externos. Es el caso del Japón que a través de elevados precios, logra adquirir especies en peligro de extinción (locos, algas, erizos). 
- La falta de capacidad de fiscalización del Estado.

A todo lo anterior, es preciso agregar la contaminación marina costera, hecho bien conocido en el país que, en algunos casos, ha alcanzado niveles críticos. Ello consiste en la introducción en el ambiente marino de sustancias con efectos venenosos que implican peligros para los recursos vivientes y para la salud humana.

La industria reductora de productos marinos (elaboraderos de harina de pescado) es una contaminación de mares, aire y habitat urbano más importantes. Como consecuencia de ello, existe una grave contaminación marina, tanto en el norte como en el sur del país (Arica, Iquique, Tocopilla, Mejillones, Caldera, Talcahuano, San Vicente y Coronel). En la bahía de Talcahuano, el canal El Morro, está catalogado como uno de los cinco focos de mayor contaminación en el mundo.

Las condiciones de trabajo en la industria pesquera muestran también grandes deficiencias. Se utiliza mucho el pago de un salario base, más rendimiento. Se han comprobado serios discriminarios salariales entre los sexos, en perjuicio de las mujeres. Predomina, además, condiciones y medio ambiente laboral riesgosos y precarios. El 40\% del empleo el las plantas de procesamiento con destino al consumo humano, es eventual y bajo estas condiciones, trabaja la mayor parte de las mujeres, con horarios de diez a doce horas, incluyendo sábados y domingos.

\section{El modelo exportador y el sector forestal}

Otro sector del modelo exportador en que la búsqueda de la ganancia a corto plazo va, en el largo plazo, en desmedro del país es el sector forestal. Se está condenando a los bosques nativos de Chile a la misma suerte catastrófica que han corrido los bosques autóctonos de otras partes del mundo.

El sector forestal se desarrolló, desde 1975, sobre la base de la privatización de los activos del Estado a precios de liquidación, transferencia de ingentes recursos fiscales al sector privado, mediante subvenciones y mecanismos de conversión de la deuda externa, políticas preferenciales en materia de salarios, relaciones laborales, créditos, precios, cambios y aranceles.

A todo esto, se agrega la despreocupación ambiental que es y será la más onerosa para el país. Tanto en el bosque como en las plantas industriales, las empresas de este sector trabajan casi sin ninguna reglamentación.

La fabricación de pulpa genera tasas muy elevadas de beneficio por unidades de materia prima. Esto incentiva a una actividad que tiene un ingente impacto ambiental, desde un extremo al otro del ciclo productivo, puesto que la 
producción de pulpa produce desechos contaminantes que afectan seriamente a los ecosistemas marinos y de agua dulce. En Chile, la pulpa representa más del $50 \%$ de la producción de todo el sector forestal. Sin embargo, de los US\$ 1.400 millones invertidos hasta ahora, sólo US\$ 120 millones (menos del 10\%) han sido destinados a adoptar procesos productivos limpios.

El proyecto de ley sobre recuperación del bosque nativo y fomento forestal languidece en el Congreso desde abril de 1992. El Estado reconoce que los planes de manejo forestal parecen, más bien, planes de cosecha, pero aduce que no tiene recursos para fiscalizarlos.

Los bosques e los renovales que están siendo destruidos por la tala rasa, por el corte selectivo o por incendios, también son utilizados para la extracción de leña, maderas de construcción, postes, durmientes y un porcentaje alto se usa, actualmente, para la fabricación y exportación de astillas. Los interesados en explotarlo, con el argumento de que el bosque está sobremaduro y degradado, promueven continuar la tala de los bosques naturales para dar lugar al monocultivo forestal de plantación. Pero estas plantaciones no son bosques, sino fábricas de árboles incapaces de prestar las garantías ecológicas de los bosques naturales (regulación del clima, influyendo directamente sobre la temperatura, la humedad y la generación de lluvias, protección de cuencas de ríos, lagos y otras fuentes de agua dulce, fuerte diversidad biológica).

El actual modelo de crecimiento del sector forestal hace un aporte escaso al progreso socio-económico de las áreas en que está concentrado y contribuye, de una manera brutal, a la continua pérdida de los territorios ancestrales de las poblaciones indígenas.

En materia de puestos de trabajo, contribuye de un modo mínimo al empleo y a medida que avanza suprime empleos. Además, el aislamiento y la baja sindicalización de los trabajadores, particularmente en el caso de los que hacen la faena de montes, convierte a los trabajadores en parte casi invisible del debate forestal.

\section{Desaparición para otros fines más rentables de la escasa tierra agrícola del país}

De los 75 millones de hectáreas de la superficie total de Chile, menos del $10 \%$, apenas cinco millones son hectáreas arables, y de estás, poco más de dos millones son tierras sin limitaciones serias para la producción agrícola. Los cultivos sólo ocupan el $2 \%$ del territorio nacional, uno y medio millones de hectáreas y están ubicados en las mejores tierras del país.

Pues bien, la rentabilidad del mercado está haciendo que en muchas de las 
mejores zonas agrícolas del país (Región Metropolitana, por ejemplo) una buena parte de estas tierras agrícolas están desapareciendo para siempre, dedicadas a urbanizaciones, parcelas week end de 5 mil metros y otras finalidades, sin que el Estado haga nada para evitarlo. Toda la legislación que existía anteriormente para impedir este desastre para el escaso capital productivo agrícola de Chile fue abolida por la dictadura y los gobiernos democráticas no han hecho nada para corregir este crimen contra el patrimonio nacional. Esta es una de las consecuencias del neoliberalismo imperante que se pagará muy caro en el futuro.

En la sola región metropolitana casi 50 mil hectáreas de tierras fueron subdivididas en 1994, el 70\% de las tierras agrícolas restantes están contaminadas con aguas servidas.

\section{Mercado de trabajo flexible, pobreza}

$y$ desintegración social en Chile (1990-94)

La experencia de Chile durante la dictadura (1973-1990) fue un proceso radical para abrogar la legislación laboral existente con anterioridad y facilitar la puesta en marcha de la política neoliberal.

El nuevo código de trabajo promulgado en 1987 es extraordinariamente limitativo para los derechos de los trabajadores y se justificó aduciendo:

- el encarecimiento artificial de la contratación de la mano de obra;

- el poder monopólico de los sindicatos;

- el imperativo de las empresas de contar con la flexibilidad salarial y numérica requeridas para una economía abierta a la competencia externa;

- la necesidad de ensanchar los espacios de libertad personal constreñidos por la legislación laboral previa a 1973.

Eliminar estas rigideces en el mercado del trabajo permitiría bajar los costos, promover la inversión y disminuir el desempleo.

$\mathrm{Al}$ asumir el poder los gobiernos democráticos mantuvieron la política anterior de estabilidad macroeconómica como la mejor fórmula para alcanzar un crecimiento sostenido y conservaron, también, la orientación hacia la internacionalización de la economía, tanto en el plano comercial, como financiero. Procuraron, al mismo tiempo, corregir algunas de las consecuencias sociales del modelo neoliberal con un esfuerzo social creciente en los campos de salud, vivienda y educación, pero dentro de los límites de un gasto fiscal equilibrado.

Se mantuvo la legislación de trabajo de la dictadura por temor que su modificación, al encarecer el costo de una mano de obra barata y, en gran parte 
temporal, por el movimiento reivindicativo de los trabajadores, afectara las exportaciones, sobre todo de productos primarios.

A pesar de algunas leyes de reforma del Código del trabajo, la falta de una voluntad política más firme de parte de los gobiernos democráticos y la existencia de una mayoría opositora por el mecanismo de los senadores designados, han impedido una reforma más sustancial de la legislación laboral.

El balance de los especialistas sobre la capacidad de las reformas laborales del período 1990-94, para modificar significativamente la esencia del Código del trabajo de 1987 es desalentador. Las líneas generales de desprotección de los trabajadores permanecen, fundadas en el mismo espíritu anterior, favoreciendo crecientemente la flexibilización como criterio rector para definir los salarios, los empleos y las condiciones y calidad del trabajo.

Para los trabajadores estables, las reformas laborales sobre terminación del trabajo y estabilidad del empleo, centrales sindicales, negociación colectiva, fondo de capacitación y formación sindical, protección de los trabajadores etc., han temperado los aspectos más abiertamente represivos del Código de 1987, pero para la masa de trabajadores que realizan trabajos domiciliarios, temporales, subcontratados a plazo fijo - entre ellos las mujeres, jóvenes y niños - las reformas laborales tienden a avalar y normar las prácticas de trabajo flexible que, de hecho, ya venían utilizando los empresarios.

Las características del mercado de trabajo, de acuerdo con la política neoliberal imperante, son hoy las siguientes: la existencia de una gran masa de ocupados empobrecidos, ubicados en empleos precarios, con bajos niveles de protección, que se encuentran en nivel o por debajo de la línea de la pobreza. Imposibilidados de asegurar su mínimo de vida en condiciones satisfactorias, se ven obligados a empujar a otros miembros del grupo familiar a que se integren al mercado de trabajo para complementar los ingresos de las familias. Esto implica un gran número de personas que entran y salen del mercado de trabajo, ubicándose en empleos temporales. Ello amplía el número de la mano de obra barata, presionando a la baja de los salarios. Dentro de esta mano de obra temporal y barata, las mujeres juegan un rol muy importante. Entre 1990 y 1992, la fuerza de trabajo femenina aumentó de 1.581 .500 a 1.712 .744 .

En 1992, el 45,5\% de los ocupados recibían menos del doble del salario mínimo necesario para superar la línea de la pobreza.

En cuanto a los trabajadores organizados sindicalmente su proporción, no sólo es muy baja, sino que ha venido disminuyendo. En 1992 había 724 mil trabajadores sindicalizados sobre una fuerza de trabajo total de 4,773 millones (el 15,2\%), y en 1993 su número se había reducido a 684 mil sobre una fuerza 
de trabajo de casi 5 millones (el 13,7\%). La sindicalización es más baja en los sectores que concentran mayores fuerzas de trabajo: agricultura y servicios, excluído comercio.

El combate a la pobreza, en el que los gobiernos democráticos han logrado un cierto éxito, como vimos anteriormente, se ha centrado, sobre todo, en la incorporación de los pobres al mercado de trabajo, no considerando la existencia de una legislación laboral mucho más favorable a los empresarios que a los trabajadores, pero el hecho de que existe una amplia proporción de pobres que son asalariados muestra que, aún cuando se mantenga un acelerado ritmo de crecimiento de la economía y un aumento del empleo, ellos no bastaran para resolver el problema de la pobreza, si no se aumenta considerablemente la capacidad de negociación de los asalariados.

La muy desigual distribución del ingreso existente en el país muestra que existe un margen importante para ello. Los años de la dictadura significaron un enorme concentración del ingreso hacia los más ricos. Entre 1978 y 1990, el $40 \%$ más pobre de la población vio su participación en el ingreso total quedar estancada en un 7\%, mientras que la participación del 10\% más rico aumentó de un 30 a 37,2\%. Y esta situación no se ha corregido mucho con posterioridad.

\section{La formulación de un modelo alternativo}

La necesidad de modificar de un modo mucho mas sustancial de lo que se ha hecho hasta ahora el modelo neoliberal aplicado en Chile demanda la formulación de un modelo alternativo.

Los ejemplos de las consecuencias sociales del modelo económico neoliberal muestran la necesidad de modificarlo de un modo más sustancial que lo que se ha hecho por parte de los gobiernos post dictadura. Todo ello en función de la realización que una sociedad más democrática, menos inequitativa y más preocupada de la defensa de su capital básico, que son sus recursos naturales.

La primera modificación es de tipo conceptual. No se trata de abandonar la economía de mercado. Hoy día es la única viable, tanto en el plano nacional como internacional. Pero sí, se trata de reubicarla en un contexto que permita corregir las desigualdades que produce el mercado y su despreocupación por los problemas del mediano y largo plazo. Este contexto comprende cuatro elementos complementarios:

- El mercado, que debe conservarse como elemento de orientación y de sanción de las actividades económicas.

- El Estado, que debe fijar las grandes orientaciones del desarrollo y corregir los efectos negativos del mercado. 
- La negociación social entre actores bien organizados, que debe ser el parámetro esencial para definir los objetivos y las modalidades del desarrollo.

- Un sistema de seguridad social, que garantice a cada ciudadano derechos mínimos en materia de acceso a la salud, a la educación, a la vivienda y a una previsión digna para cuando no pueda más trabajar.

En segundo, tampoco será necesario abandonar la orientacióna hacia la exportación como uno de los ejes esenciales del crecimiento, pero estas exportaciones tendrán de orientarse con mucho mayor intensidad que hasta ahora hacia manufacturas y servicios y menos hacia materias primas y recursos naturales. Estas dos últimas categorías constituyen, aún en 1994, más de los dos tercios del valor total de las exportaciones chilenas.

Los neoliberales confunden la estrategia de crecimiento basada en las exportaciones con la apertura económica indiscriminada y abrupta. La apertura es necesaria, pero debe ser selectiva y gradual y apoyándose, muy fuertemente, en las exportaciones industriales.

Ni Chile, ni ningún país latinoamericano puede ser competitivo en todas las ramas de la economía. Por ello, es esencial que se formen instituciones gubernamentales de marketing y evaluación de las tendencias internacionales, a efecto de detectar, en íntima relación con la empresa privada, nichos de mercado en el campo internacional y poner en marcha políticas industriales y comerciales apropiadas.

Debe desecharse la idea favorita de los neoliberales que la integración en los mercados internacionales debe lograrse de acuerdo con las ventajas comparativas actuales. Como lo señala muy bien el economista José Luis León, de la Universidad de Columbia: "Si el Japón hubiese confiado por completo en esta estrategia, sus exportaciones actuales serían artesanías, pescados y mariscos, y tal vez sake; si Taiwán y Corea del sur se hubiesen atenido a sus ventajas comparativas, sus exportaciones actuales serían caña de azúcar, productos tropicales y, tal vez, ron. Es tiempo de entender que el mercado no va a ser por sí mismo lo que nosotros no diseñemos en políticas de desarrollo y comercio internacional, deliberada y estratégicamente orientadas. Aún cuando la tentación de utilizar los recursos naturales y la mano de obra barata como ventajas en el mercado internacional es grande, ni unos ni otra pueden considerarse como ventajas competitivas a largo plazo".

Un punto esencial para prolongar la competitividad chilena en el mercado mundial será terminar con la confusión entre el desarrollo basado en las exportaciones y las políticas de desprotección y apertura radical. 
La tercera modificación esencial de una estrategia alternativa al actual modelo neoliberal es la reforma del Estado, no sólo en su tamaño, sino también en su concepción, sus estilos y técnicas administrativas, sus mecanismos de reclutamiento y ascenso y su relación a los diversos sectores de la sociedad.

Se trata de desarrollar un Estado austero, eficiente y con claro concepto de sus responsabilidades en el mediano y largo plazo. Deberá, por un lado, defender eficazmente el patrimonio de los recursos naturales del país, malgastados de una manera criminal hoy día, como hemos visto anteriormente, por el desarrollo neoliberal. Deberá, por otra parte, promover un sistema de seguridad social que, sin ser burocrático, garantice en forma eficiente el acceso a la salud, a la educación, a la vivienda y a la previsión, particularmente a los sectores más postergados de la sociedad (el tercio de los más pobres).

Deberá, en materia de formación de recursos humanos, recordar que el éxito logrado hoy día por los nuevos países industriales de Asia está asociado a un nivel de educación secundaria de calidad, extensiva a toda la población y no profundamente discriminatorio, como es el actual modelo existente en Chile. Deberá saber establecer los vínculos entre el sector público, el sector privado y el universitario de formación e investigación, que es básico para la modernización y el desarrollo.

En materia de facilidades a la inversión extranjera, deberá tener en cuenta que las empresas multinacionales, al menos en los sectores más productivos y rentables, buscan algo distinto de los salarios bajos y los recursos naturales abundantes, definidos hoy como nuestras principales ventajas comparativas. Una redefinición en este sentido tendrá de aceptar que una mejor infraestructura, una eficiente red de telecomunicaciones y transportes y una mano de obra capacitada, gracias a altos niveles de educación formal e informal, serán la mejor manera, no sólo de atraer capitales extranjeros, sino también de lanzarse hacia un desarrollo con cimientos para el largo plazo. Mientras la inversión extranjera productiva no llega en la proporción deseada, la inversión especulativa en portafolio favorecida, en gran parte, por la acelerada liberalización de los mercados financieros está a la orden del día y ha colocado a algunos países en una situación de extremada vulnerabilidad frente al exterior, como es el caso hoy día, de México. La crisis mexicana, extendida a todo el resto de América Latina, se explica principalmente por la volatividad de los capitales que, por muchos años, ha captado la región. Los US\$ 62 mil millones colocados por inversionistas internacionales en Latinoamérica hasta 1994 son uno de los factores que más desestabilizaron las economías regionales, puesto que, en buena parte, son capitales especulativos que se retiran rápidamente cuando se avistan problemas. Sólo US\$ 1 de cada US\$ 3 que, hasta hace poco, ingresaban a las economías locales se destinó a inversión real. Los otros US\$2, según Ricardo French-Davis se perdieron en la 
demanda agregada, desplazaron ahorro interno, presionaron el cambio y estimularon el consumo de productos importados.

Estos son, además de muchos otros, algunos de los aspectos a considerar en un modelo alternativo de desarrollo al actual modelo neoliberal.

Jacques Chonchol, engenheiro agrônomo, foi perito da Organização das Nações Unidas para a Agricultura e Alimentação (FAO) entre 1957 e 1961, período em que efetuou várias missões na América Latina. De 1964 a 1969 dirigiu o Instituto de Desenvolvimento da Agricultura (Indap) por indicação de Eduardo Frei, então presidente da República do Chile. Participou da fundação da Ação Popular Unificada (Mapu), que integrou a União Popular, responsável maior pela eleição de Salvador Allende. A partir de novembro de 1970, passou a ocupar a pasta da Agricultura do novo governo. Foi diretor do Institut des Hautes Études de l'Amérique Latine, em Paris, onde, em 1994, concedeu entrevista ao editor de Estudos Avançados, professor Alfredo Bosi, publicada no número 21. 